pendent and tissue-dependent differential sensitivity of mitochondrial swelling rather than of mitochondrial function in general. Thus different mitochondrial properties appear to have differential sensitivity towards hyperglycaemia. Without knowing the molecular mechanism(s) linking free radicals to mitochondrial swelling this cannot be addressed experimentally.

We conclude that hyperglycaemia-induced high-amplitude swelling is not a general phenomenon in embryonic tissues.

Yours sincerely,

C.J.P. Jones, U. Weiss, C.M. Simán, G. Desoye

\section{References}

1. Nishikawa T, Edelstein D, Du XL et al. (2000) Normalizing mitochondrial superoxide production blocks three pathways of hyperglycaemic damage. Nature 404: 787-790

2. Yang X, Borg LAH, Siman CM, Eriksson UJ (1998) Maternal antioxidant treatments prevent diabetes-induced alterations of mitochondrial morphology in rat embryos. Anat Rec. 251: 303-315
3. Yang X, Borg LAH, Eriksson UJ (1995) Altered mitochondrial morphology of rat embryos in diabetic pregnancy. Anat Rec 241: 255-267

4. Blaschitz A, Weiss U, Dohr G, Desoye G (2000) Antibody reaction patterns in first trimester placenta: implications for trophoblast isolation and purity screening. Placenta 21: 733-741

5. Payne CM, Satterfield VF (1980) A simple procedure for the preparation of rosetted cells for electron microscopy. J Clin Pathol 33: 505-508

6. Simán CM, Sibley CP, Jones CJP, Greenwood SL (2000) Cultured placental villous explants regenerate a syncytiotrophoblast with normal physiologic function. J Soc Gynecol Investig 7 [Suppl]: 136A Abstract

7. Goda N, Suematsu M, Mukai M et al. (1996) Modulation of mitochondrion-mediated oxidative stress by nitric oxide in human placental trophoblastic cells. Am J Physiol 217: H1893-H1899

8. Weiss U, Cervar M, Puerstner P et al. (2001) Hyperglycaemia in vitro alters the proliferation and mitochondrial activity of the choriocarcinoma cell lines BeWo, JAR and JEG-3 as models for human first trimester trophoblast. Diabetologia 44: 209-219

\title{
High glucose-induced intercellular adhesion molecule-1 (ICAM-1) expression through an osmotic effect in rat mesangial cells is PKC-NF- $\varkappa B$-dependent
}

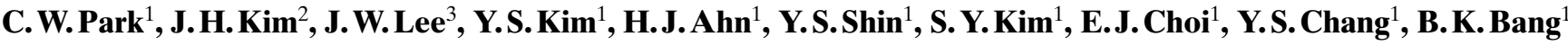 \\ ${ }^{1}$ Division of Nephrology, Department of Internal Medicine \\ ${ }^{2}$ Department of Obstetrics and Gynecology, The Catholic University of Korea, Seoul, Korea \\ ${ }^{3}$ Department of Biochemistry, The Catholic University of Korea, Seoul, Korea
}

Diabetologia (2000) 43: 1544-1553

The third author's name should read: J.H. Lee 